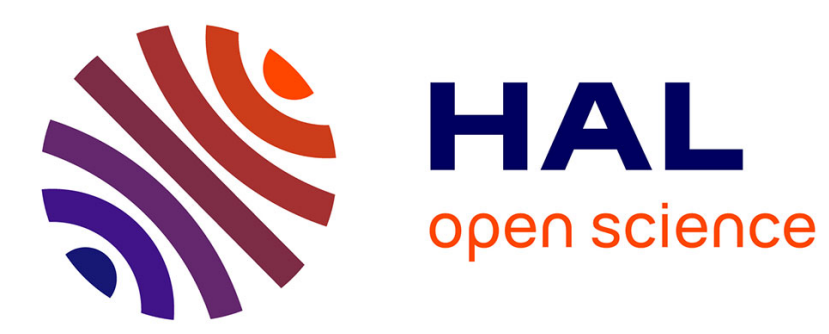

\title{
The treatment of rheumatoid arthritis during pregnancy
}

Rosamund Partlett, Euthalia Roussou

\section{To cite this version:}

Rosamund Partlett, Euthalia Roussou. The treatment of rheumatoid arthritis during pregnancy. Rheumatology International, 2010, 31 (4), pp.445-449. 10.1007/s00296-010-1643-7 . hal-00646916

\section{HAL Id: hal-00646916 https://hal.science/hal-00646916}

Submitted on 1 Dec 2011

HAL is a multi-disciplinary open access archive for the deposit and dissemination of scientific research documents, whether they are published or not. The documents may come from teaching and research institutions in France or abroad, or from public or private research centers.
L'archive ouverte pluridisciplinaire $\mathbf{H A L}$, est destinée au dépôt et à la diffusion de documents scientifiques de niveau recherche, publiés ou non, émanant des établissements d'enseignement et de recherche français ou étrangers, des laboratoires publics ou privés. 


\section{The Treatment of Rheumatoid Arthritis during Pregnancy}

Rosamund Partlett 1, Euthalia Roussou1,2

1. Bart's and The London School of Medicine and Dentistry

2. Department of Rheumatology and Rehabilitation

Barking Havering and Redbridge University Hospitals NHS Trust

King George Hospital, Barley Lanes, Goodmayes, Essex IG3 8YB, UK

\section{*Corresponding author}

Dr. Euthalia Roussou

Department of Rheumatology and Rehabilitation, King George Hospital, Barley Lane, Goodmayes, Ilford, Essex, UK IG3 8YB

E-mail address: thaliaroussou@hotmail.com

Tel.: 00442089704227

Fax: 00442089708189

Key words: review, treatment, pregnancy, Rheumatoid Arthritis. 


\section{Abstract}

There are a wide variety of medications available to treat patients with rheumatoid arthritis, many of which are considered unsafe during pregnancy It is important to tailor a treatment regimen that stabilises the woman's disease prior to conception, using medications that are safe to continue throughout pregnancy and the postpartum period

Drugs that may be safely used during pregnancy include NSAIDs, corticosteroids, plus several DMARDs, including sulfasalazine and hydroxychloroquine

Drugs recommended to be stopped before pregnancy include methotrexate and leflunomide, plus the biologics: anti-TNF agents, rituximab and abatacept 


\section{Introduction}

Rheumatoid arthritis is a relatively common disease, affecting approximately $1 \%$ of the population. Rheumatoid arthritis occurs more frequently in women than men, and tends to present in women of childbearing age, with disease frequency rising with increasing age [1]. Thus, a significant number of patients with rheumatoid arthritis fall pregnant, posing a therapeutic challenge to the healthcare professionals managing their disease.

It has been shown that disease activity in rheumatoid arthritis often dampens down during pregnancy with a subsequent flare-up post-partum. However, a recent prospective study has demonstrated extensive variation in the effect that pregnancy may have on rheumatoid arthritis, with only $16 \%$ of study participants experiencing complete remission during pregnancy and $>25 \%$ suffering considerable disability [2]. The postpartum period is also a common time for women to present for the first time with rheumatoid arthritis [3]. Therefore, many pregnant women with rheumatoid arthritis will require some form of treatment to ameliorate their disease during pregnancy and the postpartum period, and it is important to be aware of the treatments that are safe during pregnancy and those that are not. This piece of work will briefly explore the effects that commonly-used drugs in rheumatoid arthritis have during pregnancy, and therefore determine which medications may be continued in pregnancy and which medications must not. It is important to recognise that robust evidence is limited due to the understandable lack of evidence-based data in this particular field, with much of the current guidelines being based upon small case studies and anecdotal evidence.

In the USA, the US Food and Drugs Administration (FDA) pregnancy category is relied upon to guide treatment decisions during pregnancy:

\begin{tabular}{|c|c|}
\hline FDA Category & Classification \\
\hline A & Controlled studies show no risk \\
\hline B & No evidence of risk in humans \\
\hline C & Risk cannot be ruled out \\
\hline D & Positive evidence of risk \\
\hline X & Contraindicated in pregnancy \\
\hline N & Not rated \\
\hline
\end{tabular}


Clearly, it is preferable for pregnancy in women with rheumatoid arthritis to be planned, allowing optimisation of therapy that it is compatible with pregnancy and achieving stable disease before conception. This maximises the chances of a safe pregnancy and healthy infant. However, it is inevitable that a proportion of women receiving medications for their rheumatoid arthritis will unexpectedly fall pregnant, posing a challenges to both the rheumatologist and patient.

\section{$\underline{\text { Anti-inflammatory agents }}$}

\section{Non-steroidal anti-inflammatories (NSAIDs)}

NSAIDs are taken to improve joint pain and stiffness in rheumatoid arthritis. There has been considerable research examining the effects of NSAIDs during pregnancy and based on this, the FDA classifies them as either category B or C, depending on the specific drug. NSAIDs do not cross the placenta, but there is some debate as to the level of teratogenic risk they pose. Some studies have demonstrated an increased risk of cardiac septal defects and gastroschisis in infants exposed to NSAIDs in utero [4], but several large population-based cohort and case-control studies based in Europe and the USA have not found any increased risk of congenital abnormalities associated with non-selective COX inhibitors during pregnancy [5,6]. NSAIDs act to inhibit prostaglandin synthesis, thus they can promote premature closure of the ductus arteriosus leading to pulmonary hypertension. Finally, administration of indamethacin, ibuprofen, naproxen and others during the third trimester have been associated with renal dysgenesis and subsequent oligohydramnios, necessitating immediate maternal withdrawal of the NSAID. In consideration of these complications, current recommendations advise low-dose NSAIDs until 32 weeks gestation to avoid complications [6-8].

\section{Corticosteroids}

Steroids are an extremely useful means of rapidly suppressing an acute flare-up of rheumatoid arthritis, including during pregnancy. However, it has an FDA category of $\mathrm{C}$ due to the well-recognised complications of intrauterine growth restriction, prematurity and infection, which appear to be dose-related [8]. Furthermore, corticosteroid exposure during the first trimester has recently been linked with a modestly increased risk of cleft palate. In clinical practice, low-dose oral 
corticosteroids are recommended, for example 5-15mg prednisolone, in order to avoid these dose-related complications during pregnancy [6-8].

\section{Disease-modifying anti-rheumatic drugs (DMARDs)}

DMARDs act to suppress disease activity and slow the erosive joint damage that rheumatoid arthritis causes. Many of the drugs in this class act to suppress the immune system however, the mechanisms of action for some are not fully understood.

\section{Methotrexate}

Methotrexate is the methyl derivative of aminopterin, a folate antagonist. Both these compounds are teratogenic, inflicting a characteristic collection of abnormalities in neonates exposed in utero. The pattern of congenital abnormalities is known as the aminopterin/methotrexate syndrome, and includes: growth deficiency, hypoplastic supraobrital ridges, abnormal cranial ossification, small low-set ears, micrognathia, and limb abnormalities [8]. Methotrexate is most damaging at 5-8 weeks gestation, although fetal abnormalities have been noted outside of this period. Exposure to $\leq 20 \mathrm{mg}$ methotrexate weekly during the first trimester has been reported in 101 pregnancies [6]. Within this cohort, there were 20 miscarriages and abortions were performed in 18 women. Of the pregnancies that reached full term, five infants were born with congenital abnormalities, including one child that suffered the aminopterin/methotrexate syndrome. Consequently, methotrexate is classified as category $\mathrm{X}$ by the FDA. It is recommended that women stop methotrexate at least three months before attempting conception, due to its prolonged preservation in the tissues, and wait for at least one menstrual cycle after withdrawal of the drug.

\section{Sulfasalazine}

Sulfasalazine is another folate antagonist, used both for rheumatoid arthritis and other arthritides, as well as in the control of inflammatory bowel disease (IBD). The effects of sulfasalazine have been most widely investigated in pregnant patients with IBD, where studies have shown no suggestion of an increased risk of congenital abnormalities or adverse birth outcomes [6-8]. Hernandez-Diaz et al did find a twofold to threefold increase in neural tube defects, cardiovascular defects and cleft 
palates associated with sulfasalazine exposure in utero however, the study only included a small number of women taking sulfasalazine, and thus it is hard to draw conclusions from [9]. Reflecting these conflicting studies, the FDA has alternated the classification of sulfasalazine between B to D however, based on the available data it is widely accepted that sulfasalazine is relatively safe during pregnancy at low doses and with concomitant folic acid supplementation [6-8].

\section{Leflunomide}

Leflunomide is a pyrimidine synthesis inhibitor. In studies involving pregnant rats and rabbits, leflunomide has been shown to increase the risk of teratogenicity and embryonic death. For this reason, the FDA has classified it as category X. However, case reports and small case series have not demonstrated any such risk in humans [68]. The sole prospective controlled trial involving leflunomide during pregnancy, conducted by the Organisation of Teratology Information Specialists (OTIS), was unable to demonstrate an increased risk of teratogenicity, though there was a slightly increased risk of prematurity [6]. Due to the lack of data on leflunomide in pregnancy, it is generally recommended that women stop leflunomide two years before planning conception or undergo a washout procedure, as its active metabolite has a very long half-life.

\section{Hydroxychloroquine}

This anti-malarial is a useful DMARD to treat mild rheumatoid arthritis. Much of the literature regarding its use during pregnancy is in its role as malaria prophylaxis at low doses $(300 \mathrm{mg} /$ week), when it is not associated with an increased risk of congenital abnormalities or pregnancy loss [8-10]. However, hydroxychloroquine is used at much higher doses in the treatment of rheumatoid arthritis, prompting further research into its effects during pregnancy. One case report raised concerns about its safety, describing malformations of the inner ear and other abnormalities following chloroquine exposure throughout pregnancy in three children of a mother with systemic lupus erythematosus (SLE) [6]. Subsequent studies have disputed this finding and it is now widely believed that chloroquine is not associated with congenital abnormalities, nor long-term hearing, visual, growth or development abnormalities $[6,8,10]$. However, the theoretical risks of ototoxicity and 
oculotoxicity in the foetus means the FDA have classified hydroxychloroquine as category C.

\section{Azathioprine}

Azathioprine is not used as a first-line agent in the treatment of rheumatoid arthritis, due to its lower efficacy and high rate of adverse effects. The majority of evidence for its use during pregnancy arises from studies in pregnant transplant recipients, and in all the available literature there has been no reported increase in structural abnormalities, although studies have shown associations with prematurity and intrauterine growth restriction [6,8]. It is possible these outcomes are related to the mother's transplant status rather than her medications. Thus, currently azathioprine may be used during all stages of pregnancy and has an FDA classification of D.

\section{Ciclosporin}

Similarly to azathioprine, ciclosporin is not a first-line agent in the management of rheumatoid arthritis, and as such as the majority of data on its safety in pregnancy comes from research involving transplant recipient patients [8]. Work shows there is no increase in congenital abnormalities in neonates exposed in utero to ciclosporin, although there is again an increased frequency of prematurity and growth restriction that may be associated with the mother's transplant status. Thus, ciclosporin is considered a relatively safe drug during pregnancy, although its long-term effects require further investigation $[6,8]$.

\section{$\underline{\text { Biologics }}$}

These are relatively new drugs used to treat rheumatoid arthritis when first-line therapies have failed, and consequently there is a paucity of data regarding the use of these drugs during pregnancy. The majority of information is derived from isolated case studies and retrospective studies, thus the evidence presented is not robust.

Tumour necrosis factor (TNF)-inhibitors (etanercept, infliximab and adalimumab)

A case report followed three women who unexpectedly fell pregnant whilst taking anti-TNF therapy and showed no evidence of teratogenicity or increased risk of pregnancy loss. Of the two women in this report who chose to continue with their 
pregnancy, the only complications encountered were prematurity, neonatal jaundice and neonatal urinary E. coli infection. One of the infants did suffer adrenal congenital hyperplasia believed to be hereditary [11]. Of women who had not taken anti-TNF therapy prior to pregnancy, the literature reports more than 200 patients exposed to infliximab, more than 100 patients exposed to etanercept and approximately 50 exposed to adalimumab. Most of these women only took anti-TNF therapy during the first trimester, which is important as from the second trimester onwards significant transplacental uptake of infliximab and adalimumab is observed. Studies have shown similar rates of miscarriage and congenital abnormalities in exposed and non-exposed infants, although the frequency of prematurity and low birth weight is consistently higher in rheumatoid arthritis patients compared to controls $[6,8,12]$. There have been reports of congenital abnormalities following exposure to infliximab and etanercept in utero, including two infants with VACTER (V: vertebrae malformation; A: anal anomalies; $\mathrm{C}$ : cardiac anomalies; $\mathrm{T}$ : tracheal problems; $\mathrm{E}$ : oesophageal problems; R: renal anomalies). However, most of the reported congenital abnormalities occur in the normal population and the numbers observed are not powerful enough to determine whether there is a definite increased rate of abnormalities in women exposed to anti-TNF therapy during pregnancy $[6,8,12]$. As there is such limited data regarding anti-TNF therapy, the FDA classifies all of these agents as category B and they are generally regarded as being safe to continue until the time of conception, at which point therapy should be stopped.

\section{Rituximab}

Rituximab is a monoclonal antibody that targets B-cells and is known to cross the placenta. There is limited data in humans regarding its safety profile during pregnancy however, of the eight existing case reports the only abnormality observed was neonatal lymphopenia and/or undetectable B-cell numbers. These infants all regained normal white cell count differentials after birth. It is important to note that these women were receiving rituximab for lymphoma and haematological disease, rather than rheumatoid arthritis, and were receiving additional cytotoxic therapy [6, 8]. From such inadequate data it is impossible to determine whether rituximab taken before conception and during the first trimester has any adverse effects on the foetus, and it appears to cause B-cell depletion in the neonate when taken during the second and third trimesters with unknown long-term effects. Consequently, the FDA classifies 
rituximab as category $\mathrm{C}$ and it is recommended that therapy should be stopped one year before conception.

\begin{abstract}
Abatacept
Abatacept is a selective co-stimulation modulator that acts to inhibit T-cell activation. There is no data at present investigating the effects of abatacept in pregnant women however, studies involving pregnant rats and rabbits exposed to doses of abatacept 11-fold greater than normal had no adverse effects on the foetus. As such, recommendations are to discontinue therapy at least 10 weeks before conception.
\end{abstract}

\title{
Conclusion
}

It is important to impress on women with rheumatoid arthritis the importance of effective contraception whilst on certain medications that are commonly used and very effective in controlling their disease. This is because there are several medications that are known to be teratogenic and others whose safety profile during pregnancy is still not well recognised.

If and when women do choose to start a family, it is crucial they discuss treatment options beforehand with their rheumatologist and together tailor a treatment regimen that stabilises their disease, using medications that pose little risk during pregnancy. Thus, certain medications that have kept their disease in remission or well-controlled may need to be withdrawn and substituted for others that are safer in pregnancy. This may cause disease flare-ups, which ideally should be managed before trying to conceive. In conclusion, pregnancy and stable rheumatoid arthritis are certainly compatible however, this is best achieved by good communication between patient and doctor and careful consideration of the management options available. 


\section{Bibliography}

1. C Deighton and R Luqmani. The NICE and BSR Guidelines on the Management of Rheumatoid Arthritis [online]. Autumn 2009; No. 4. Available from: http://www.arc.org.uk/arthinfo/medpubs/6544/6544.asp [accessed 12/01/10]

2. JH Barrett, P Brennan, M Fiddler, AJ Silman. Does rheumatoid arthritis remit during pregnancy and relapse postpartum? Results from a Nationwide Study in the United Kingdom Performed Prospectively from Late Pregnancy. Arthritis \& Rheumatism. 1999; 42: 1219-1227. Available from: http://www3.interscience.wiley.com/cgi-bin/fulltext/79503251/PDFSTART [accessed 12/01/10]

3. AJ Silman, A Kay, P Brennan. Timing of pregnancy in relation to the onset of rheumatoid arthritis [Abstract]. Arthritis \& Rheumatism. 1992; 35: 152-155. Available

from: http://www.ncbi.nlm.nih.gov/pubmed/1734904?dopt=Abstract [accessed $12 / 01 / 10]$

4. CP Torfs, EA Katz, TF Bateson, PK Lam, CJ Curry. Maternal medications and environmental exposures as risk factors for gastroschisis [Abstract]. Teratology. 1996; 54: 84-92. Available from: http://www.ncbi.nlm.nih.gov/pubmed/8948544?itool=EntrezSystem2.PEntrez. Pubmed.Pubmed_ResultsPanel.Pubmed_RVDocSum\&ordinalpos=3 [accessed $12 / 01 / 10]$

5. GL Nielsen, HT Sorensen, H Larsen, L Pedersen. Risk of adverse birth outcome and miscarriage in pregnant users of non-steroidal anti-inflammatory drugs: population-based observational study and case-control study. BMJ. 2001; 322: 266-270. Available from: http://www.bmj.com/cgi/content/full/322/7281/266?view=long\&pmid=11157 526 [accessed 12/01/10]

6. M Østensen, F Förger. Management of RA medications in pregnant patients. Nature Reviews: Rheumatology. 2009; 5: 382-390. Available from: http://www.nature.com/nrrheum/journal/v5/n7/pdf/nrrheum.2009.103.pdf [accessed 12/01/10]

7. SO Keeling, AE Oswald. Pregnancy and rheumatic disease: "by the book" or "by the doc". Clinical Rheumatology. 2009; 28: 1-9. Available from: http://www.springerlink.com/content/c7272331544204n3/fulltext.html [accessed 12/01/10]

8. CD Chambers, ZN Tutuncu, D Johnson, KL Jones. Human pregnancy safety for agents used to treat rheumatoid arthritis: adequacy of available information and strategies for developing post-marketing data. Arthritis Research \& 
Therapy. 2006, 8: 225-235. Available from: http://arthritisresearch.com/content/pdf/ar1977.pdf [accessed 12/01/10]

9. S Hernández-Díaz, MM Werler, AM Walker, AA Mitchell. Folic acid antagonists during pregnancy and the risk of birth defects. The New England Journal of Medicine. 2000; 343: 1608-1614. Available from: http://content.nejm.org/cgi/content/abstract/343/22/1608 [accessed 12/01/10]

10. N Costedoat-Chalumeau, Z Amoura, P Duhaut, DLT Huong, D Sebbough, B Wechsler, D Vauthier, I Denjoy, J-M Lupoglazoff, J-C Piette. Safety of hydroxychloroquine in pregnant patients with connective tissue diseases. Arthritis and Rheumatism. 2003; 48: 3207-3211

11. CH Roux, O Brocq, V Breuil, C Albert, L Euller-Ziegler. Pregnancy in rheumatology patients exposed to anti-tumour necrosis factor (anti-TNF)- $\alpha$ therapy. Rheumatology. 2007; 46: 695-698

12. C Chambers, G Koren, ZN Tutuncu, D Johnson, KL Jones. Are new agents used to treat rheumatoid arthritis safe to take during pregnancy? Canadian Family Physician. 2007; 53: 409-412 